\section{Help patients with compromised enamel}

As you know, dental enamel comes under constant attack, weakening and damaging its crystalline structure.

Arm \& Hammer Enamel Pro Repair baking soda toothpaste has been formulated to help patients with compromised enamel. Featuring Liquid Calcium technology, the solution has been specially engineered to help restore surface enamel by filling in micro cracks and crevices. It is an effective and cost-efficient method to help your patients remineralise and strengthen their teeth by recommending this quality toothpaste, no matter what challenges they are facing in life right now.

Help your patients keep tooth decay at bay, with Arm \& Hammer baking soda toothpastes.

For more information about the carefully formulated Arm \& Hammer toothpaste range, visit http://www.armandhammer. co.uk/ or email: ukenquiries@churchdwight.com.

Arm \& Hammer oral healthcare products are available in-store and online at Boots, Superdrug, Sainsbury's, Tesco, Asda and Morrisons throughout the UK.
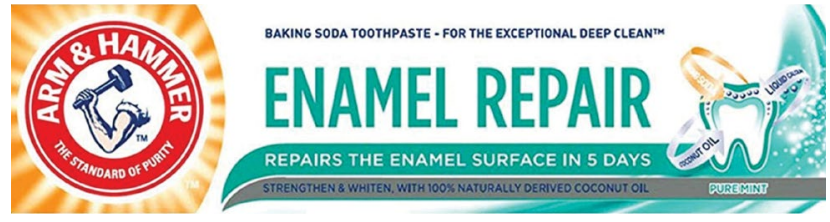

\section{For a wide array of indications}

Are you looking for a dental adhesive that not only provides excellent bond strength, but which can also be used in a wide array of indications?

Scotchbond Universal Plus Adhesive from $3 \mathrm{M}$ Oral Care is an innovative solution that offers professionals new levels of control and predictability.

Able to bond to the majority of natural and man-made dental materials, including cariesaffected dentine, Scotchbond Universal Plus Adhesive from $3 \mathrm{M}$ also forms a void-free hybrid layer that prevents secondary decay.

Plus, its innovative design means application is easier than ever, cutting down waste and reducing the risk of cross contamination with a one-unit dose delivery. It's little wonder that $3 \mathrm{M}$ Scotchbond Universal Plus Adhesive was named 'Best Universal Bonding Agent' at the 2021 Dental Advisor Awards.

For more information, call 08705 360036 or visit www.3M.co.uk/ Dental. $3 \mathrm{M}$ representatives continue to be available via video calling technologies for your convenience.

$3 \mathrm{M}$ and Scotchbond are trademarks of the $3 \mathrm{M}$ Company.

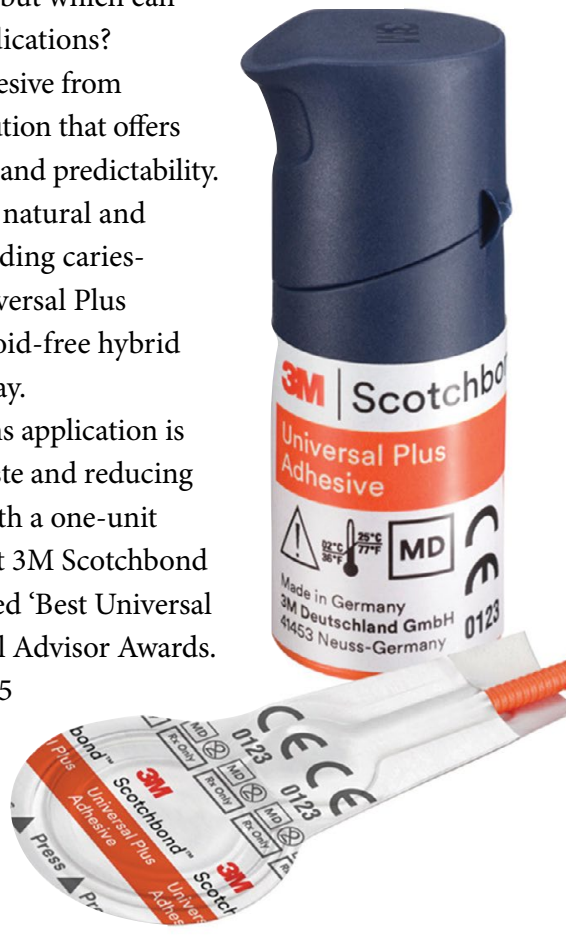

\section{Oral health that helps protect the planet}

Coming soon from premium oral hygiene brand TANDEX is the WOODI interdental brush.

The WOODI has a handle made from FSC-certified birchwood and is supplied in a recyclable cardboard box. It comes in six sizes, each identified by a unique colour.

The WOODI is part of the TANDEX commitment to respect the environment. Only food-approved raw materials are used to make its products, which are manufactured using sustainable energy sources, to reduce the carbon footprint.

TANDEX believes that oral health products should help protect the planet as well as 'keep you smiling.' To find out more, visit the website today.

For more information on Tandex's range of products, visit https://tandex.dk/.

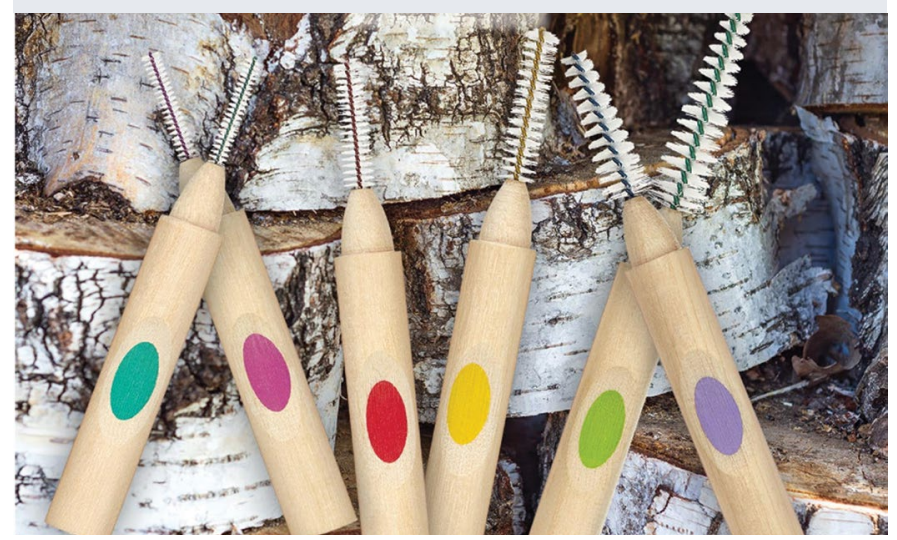

